https://helda.helsinki.fi

\title{
Random-Effects Assumption in Meta-analyses
}

\section{Hemilä, Harri}

2019-07-02

Hemilä , H 2019 , ' Random-Effects Assumption in Meta-analyses ' , JAMA : The Journal of the American Medical Association, vol. 322 , no. 1 , pp. 81-81 . https://doi.org/10.1001/jama.2019.5439

http://hdl.handle.net/10138/312604

https://doi.org/10.1001/jama.2019.5439

acceptedVersion

Downloaded from Helda, University of Helsinki institutional repository.

This is an electronic reprint of the original article.

This reprint may differ from the original in pagination and typographic detail.

Please cite the original version. 


\section{Random-Effects Assumption in Meta-analyses}

Harri Hemilä, MD, PhD

Department of Public Health

University of Helsinki, Helsinki, FINLAND

harri.hemila@helsinki.fi

https://www.mv.helsinki.fi/home/hemila/

This is a manuscript version of a letter-to-the-editor published as

Hemilä H.

Random-Effects Assumption in Meta-analyses.

JAMA. 2019 Jul 2;322(1):81.

https://doi.org/10.1001/jama.2019.5439

https://www.ncbi.nlm.nih.gov/pubmed/31265091 
To the Editor,

Repeated clinical trials on a single medical intervention are never exact replications because patients differ and there are usually some variations in the intervention and outcome measurements. Such variations can lead to inconsistent results between studies on the same intervention.

Drs Serghiou and Goodman [1] proposed random-effects meta-analysis as a solution to summarize inconsistent results. However, a long-term concern in meta-analysis has been the apples-andoranges comparison problem when studies that are too different are combined into a single estimate of effect. Random-effects meta-analysis can exacerbate this problem.

Serghiou and Goodman mentioned that many statisticians have encouraged the use of subgroup analysis to search for explanations for heterogeneity, but they devalued such an approach by stating that subgroup analyses are exploratory and their results should be interpreted accordingly.

Few meta-analyses lead to direct changes in clinical practice, but many meta-analyses can guide further research. If all inconsistent studies are combined into a single confidence interval, there is no guidance for new trials. In contrast, when a subgroup analysis finds differences in the treatment effect by certain characteristics of the trials, such findings can guide further research. I will illustrate these differences in the following examples.

One meta-analysis on vitamin $\mathrm{C}$ and postoperative atrial fibrillation used the random-effects metaanalysis approach to describe data from 13 trials and calculated that vitamin $\mathrm{C}$ was associated with a decreased occurrence of postoperative atrial fibrillation with a relative risk (RR) of 0.68 (95\% CI 0.54-0.87). However, heterogeneity was significant with an $\mathrm{I}^{2}$ of $59 \%(\mathrm{P}=0.003)$.[2] Although the confidence interval indicates that vitamin $C$ was associated with a decreased risk, at least in some hospital contexts, it is not evident which patients should take vitamin $\mathrm{C}$ or which patient groups should be investigated in further trials.

Another meta-analysis used the subgroup analysis approach and calculated that among 5 trials conducted in the United States, vitamin C did not prevent postoperative atrial fibrillation (RR 1.04; 95\% CI 0.86-1.27). However, in 9 trials conducted outside the United States in lower-income countries, vitamin $\mathrm{C}$ was associated with a decreased incidence of postoperative atrial fibrillation (RR 0.56; 95\% CI 0.47-0.67).[3] These subgroup findings indicate that new trials in the United States may be a waste of resources, whereas further research conducted in lower-income countries should be encouraged. Such conclusions cannot, however, be drawn from the single confidence interval from the random-effects meta-analysis. 


\section{References}

[1] Serghiou S, Goodman SN.

Random-effects meta-analysis: summarizing evidence with caveats.

JAMA. 2019;321(3):301-302.

https://doi.org/10.1001/jama.2018.19684

[2] Shi R, Li ZH, Chen D,Wu QC, Zhou XL, Tie HT.

Sole and combined vitamin $\mathrm{C}$ supplementation can prevent postoperative atrial fibrillation after cardiac surgery: a systematic review and meta-analysis of randomized controlled trials. Clin Cardiol. 2018;41(6):871-878.

https://doi.org/10.1002/clc.22951

https://www.ncbi.nlm.nih.gov/pmc/articles/PMC6489881

[3] Hemilä H, Suonsyrjä T.

Vitamin C for preventing atrial fibrillation in high risk patients: a systematic review and meta-analysis.

BMC Cardiovasc Disord. 2017;17(1):49.

https://doi.org/10.1186/s12872-017-0478-5

https://www.ncbi.nlm.nih.gov/pmc/articles/PMC5286679 